\title{
MRS Communications publishes inaugural article
}

\section{www.mrs.org/mrc}

M RS Communications, the recently launched journal from the Materials Research Society and Cambridge University Press, was designed to serve the fast-moving international materials research community. Focused on reporting cutting-edge materials research and offering quick turnaround at both the editorial and production stages of publication, the journal published its first article less than two months after its

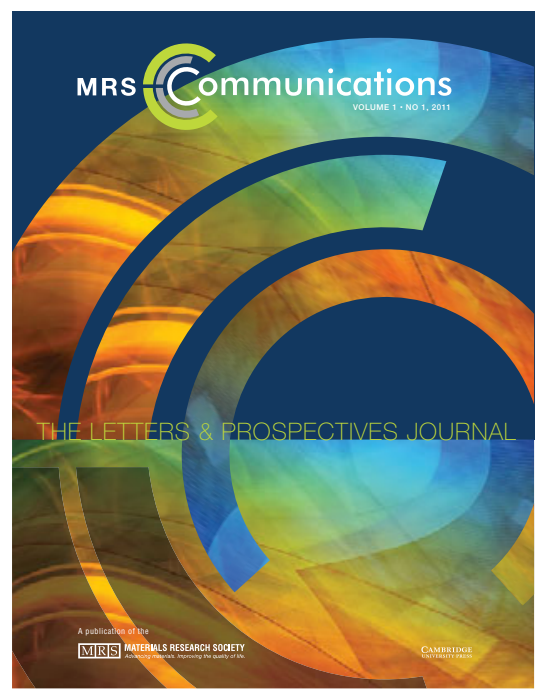

official launch at the 2011 MRS Spring Meeting in San Francisco. The inaugural Rapid Communications article details an important breakthrough by a team of Japanese and German researchers.

The researchers-Tomoyuki Yokota, Tsuyoshi Sekitani, Yu Kato, Kazunori Kuribara, and Takao Someya (The University of Tokyo); Ute Zschieschang and Hagen Klauk (Max Planck Institute for Solid-State Research); Tatsuya Yamamoto and Kazuo Takimiya (Hiroshima University); and Hirokazu Kuwabara and Masaaki Ikeda (Nippon Kayaku Co., Ltd.) - report that they have achieved a transconductance of $0.76 \mathrm{~S} / \mathrm{m}$ for organic thin-film transistors with $4 \mathrm{~V}$ operation. The team writes, "This is the highest transconductance reported for organic TFTs fabricated using printing, to the best of our knowledge." The first Rapid Communications paper (DOI: $10.1557 / \mathrm{mrc} .2011 .4$ ) is freely available on Cambridge Journals Online (CJO).

The transconductance report is the first in the new journal's Rapid Communications section (defined as a concise presentation of a study with broad inter- est showing novel results).

The first published paper shows that, thanks to ultra-low volume (subfemtoliter) inkjet nozzles, small transistors (channel length $\sim 1 \mu \mathrm{m}$ ) were fabricated using electrodes printed from nanoparticle metal inks. The small dimensions allowed the researchers to demonstrate low-power and high-speed operation (theoretically up to

MRS a few $\mathrm{MHz}$ ) of organic transistors, a requirement for useful circuits.

The researchers show that organic and printed electronics are not limited to large and slow devices, but can be extended to fast and miniaturized circuits while remaining compatible with low-cost fabrication on cheap flexible substrates. In general, these capabilities widen the spectrum of potential applications of this technology.

MRS Communications, a full-color, online-only publication, offers authors an exceptionally rapid review process and time-to-publication, while also providing a swift and direct channel to the global 16,000-strong MRS membership and to the international network of leading academic, industrial and government libraries worldwide served by Cambridge University Press. The first full issue of the journal will appear later this year.

For more information on MRS Communications, visit www.mrs.org/mrc.

IUMRS seeks nominees for 2012 Sōmiya Award

www.iumrs.org

T

he International Union of Materials Research Societies (IUMRS) is seeking nominations for the Sōmiya Award, which recognizes research on real materials conducted by a research team whose members are drawn from at least two continents. The submission deadline is February 29, 2012.

Sōmiya Award recipients are selected by the IUMRS Commission on Awards. The recipients receive an award commemorating the occasion. Next year, the ceremony will be held at the 12th IUMRS International Conference on Electronic Materials (IUMRS-ICEM
2012), September 24-28, 2012 in Yokohama, Japan.

The following criteria are used for selection:

- The team to be honored must have collaborated across at least two continents (e.g., North America, Europe, Asia, Australia) some time during the last decade.

- The collaborative work must be of the highest quality and well recognized by the international materials community.

- The impact on technology or society is also a major factor.
The annual award is named in honor of Shigeyuki Sōmiya, emeritus professor of the Tokyo Institute of Technology, and later dean at Teikyo University of Science and Engineering. Sōmiya spent his post-graduate years in the United States and embarked on a series of collaborative research and exchange visits in many countries. Among his honors are the MRS Medal and the Japanese Scientific Academic Award.

Information about the award and nomination forms are available at www. iumrs.org. 